\title{
Realizing a Null-Type Instrument to Determine the Quality of a Lamp Using Problem-Based Learning
}

\author{
Oki Dwi Saputro ${ }^{1, a}$, Muhamad Abduh ${ }^{1}$, Irfan Abdurrahman ${ }^{1}$, Elfi Yuliza ${ }^{1}$, Lilik Hasanah ${ }^{2, b}$, \\ Khairurrijal $^{1, \mathrm{c}}$ \\ ${ }^{1}$ Departement of Physics, Faculty of Mathematics and Natural Sciences, Institut Teknologi Bandung, \\ Jalan Ganesa 10, Bandung 40132, Indonesia \\ ${ }^{2}$ Departement of Physics, Faculty of Mathematics and Natural Sciences, Indonesia University of Education, \\ Jalan Dr. Setiabudi 229, Bandung 40154, Indonesia \\ akokids@students.itb.ac.id, ${ }^{b}$ lilik_hasanah@yahoo.com, ${ }^{c}$ krijal@fi.itb.ac.id
}

\begin{abstract}
Nowadays, problem-based learning (PBL) is widely implemented in many high schools and colleges. PBL is a learning method that uses a problem to stimulate learning of information and concepts introduced by the problem. In this paper, the problem is to make a null-type instrument that can be used to determine the quality of a lamp. Three students worked with a small group with a tutor who facilitates discussion and learning. The steps that have been done by the students are as follows: 1 . Encountering the problem, 2. Collecting information and learning the theory about the problem, 3. Forming and testing hypotheses about the underlying mechanisms of the problem, 4. Identifying further learning needs for making progress with the problem, 5 . Carrying out self-study between group meetings to fulfill the identified the learning needs, 6 . Returning to the group to integrate the newly gained knowledge and applying it to the problem, 7. Repeating steps 3 to 6 as necessary, and 8 . Reflecting on the process and on the content that has been learnt. After the students have performed all the steps, they also have a null-type instrument that is able to determine the quality of an energy-saving lamp. The instrument is then called as the quality-of-lamp meter.
\end{abstract}

Index Terms - Problem-based learning, Null-type instrument, Quality of lamp, Energy-saving lamp.

\section{Introduction}

Problem Based Learning (PBL) was first implemented in North America's medical schools almost thirty years ago. It is an instructional method characterized by the use of patient problems as a context for students to improve problem-solving skills and acquire knowledge about basic and clinical sciences [1]. At present, many disciplines around the world apply problem-based approaches to learning. The implementation of PBL in Mechanical Engineering and Biomedical Engineering at TU Eindhoven has shown that PBL offers good prospects in the first few years of a program, especially if group work tutorials and some directive teaching are added [2]. However, when PBL was applied in undergraduate program of Aeronautics and Astronautics at MIT, students found that learning is more interesting and engaging in all years, and that they developed a greater understanding of engineering science and core engineering fundamentals [3].

In introductory science courses in biology, physics, and chemistry, it was found that PBL provides a powerful approach [4]. Moreover, it was shown that PBL is more effective than traditional teaching methods on students' conceptual development in the $1^{\text {th }}$ class of Department of
Physics Teaching at Dokuz Eylül University, Turkey [5]. Students who partook in a thermal physics course taught through PBL found physics more interesting and relevant, their attendances rose to almost $100 \%$, and they had better achievements in exam [6]. In addition, the PBL approach used in teaching the first law of thermodynamics had a positive effect on the students' learning abilities and science process skills [7].

In this paper, we report an implementation of PBL in making a simple null-type instrument that has been done by physics undergraduate students taking the Measurements and Data Processing Techniques course at Institut Teknologi Bandung, Indonesia. The null-type instrument, which is equipped by a VU (volume unit) meter and a bridge configuration, functions to verify the quality of a lamp.

\section{Methodology}

Students work in a small group with a tutor who acts as a facilitator during discussion and learning. In making the null-type instrument for verifying the quality of lamps under the PBL approach, students have performed the following steps [8]:

i. Encountering the problem (without doing any preparation before studying the problem),

ii. Collecting information and learning the theory about the problem,

iii. Forming and testing hypotheses about the underlying mechanisms of the problem,

iv. Identifying further learning needs for making progress with the problem,

v. Carrying out self-study between group meetings to fulfill the identified the learning needs,

vi. Returning to the group to integrate the newly gained knowledge and applying it to the problem,

vii. Repeating steps 3 to 6 as necessary,

viii. Reflecting on the process and on the content that has been learnt.

\section{Results and Discussion}

A. Encountering the problem

Lamp is a very high functional device in our life. Can you imagine our life without this device? Nowadays the quality of lamps depends on companies producing them. 
This quality may vary from one company to another and we therefore decided to make a simple instrument to measure the quality of various lamps in the market. The specific goal is to verify the quality of lamps from measuring their intensities.

Light is a radiation of an electromagnetic energy packet and its intensity can be sensed by a sensor called as light dependent resistor (LDR). As reflected by its name, the change in intensity of light exposing an LDR causes the change of its resistance. Therefore, the problem is to make a lamp quality meter using an LDR as a component to convert the intensity of light into the resistance of LDR.

B. Collecting information and learning the theory about the problem

A textbook for the course [10] was used as a principal reference to make a lamp quality meter using an LDR as a component to convert the intensity of light into the resistance of LDR. Some keywords, which were obtained from the textbook and discussion with the teacher in the classroom, were then applied to generate more information under the Google search engine. It was found that bridge circuits are commonly used as a variable conversion element in measurement systems and they produce output voltages that change as the measured physical quantities change.

A bridge circuit can detect a very small change in resistance, inductance, and capacitance. Normally, excitation of the bridge circuits use a.c. voltages for inductance and capacitance measurements and a d.c. voltage for resistance measurement. The types of bridge circuits are divided into null and deflection. The null type is commonly employed for calibration purposes while the deflection one is mainly used for determining the value of measured physical quantity [10].

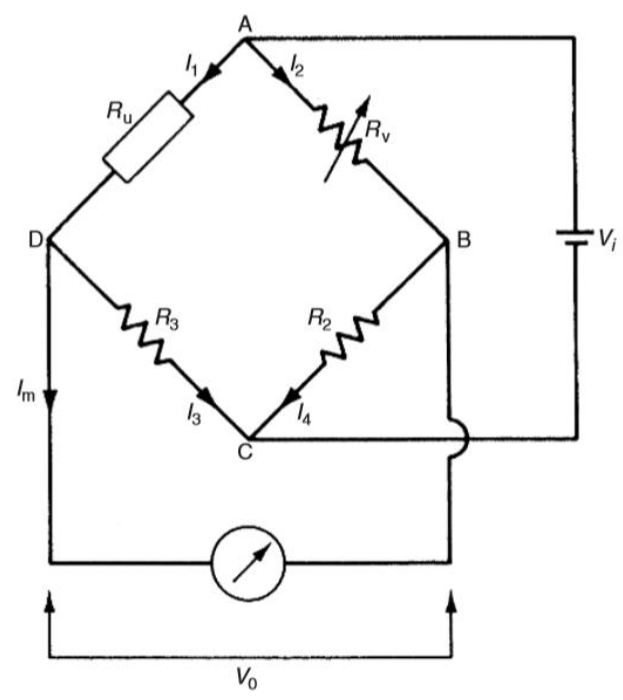

Fig 1. The null-type Wheatstone bridge [10].

For our purpose, the null-type bridge circuit with d.c. excitation, which is generally known as a Wheatstone bridge, is selected. The schematic diagram of null type bridge circuit is shown in Figure 1. The four arm of the bridge circuit is formed by 4 resistors where two equal value resistors $R_{2}$ and $R_{3}, \quad R_{v}$ is the variable resistor (potentiometer), and $\mathrm{R}_{\mathrm{u}}$ is the LDR with unknown resistance.
The d.c. excitation is provided by the battery $\mathrm{V}_{\mathrm{i}}$ applied to the points $A C$. The resistance of $R_{v}$ is varied until the voltage measured across the points $\mathrm{BD}$ is zero. This condition is called as a null point of the bridge.

A VU (volume unit) meter, which is given in Figure 2, can be used as a voltmeter. It employs a rectangular coil wound round a soft iron core that is suspended in the field of a permanent magnet. When a d.c. electric current is applied to the coil, the VU meter's pointer attached to the coil rotates and compresses a small spring. The angular rotation is therefore proportional to the current through the coil [10].

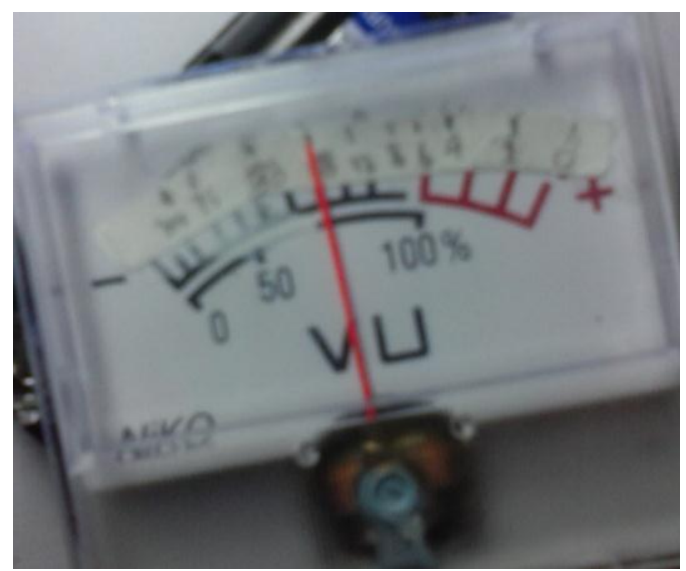

Figure 2. A VU meter.

An LDR depicted in Figure 3 consists of a zigzag cadmium sulfide (CdS) semiconductor and two electrodes connecting both sides of the semiconductor. Its resistance changes with the light intensity that falls upon it. In the dark condition, the LDR resistance was around $10 \mathrm{M} \Omega$ while in the bright light, it was $1 \mathrm{k} \Omega$ or less. This means that the LDR resistance decreases with light intensity [9].

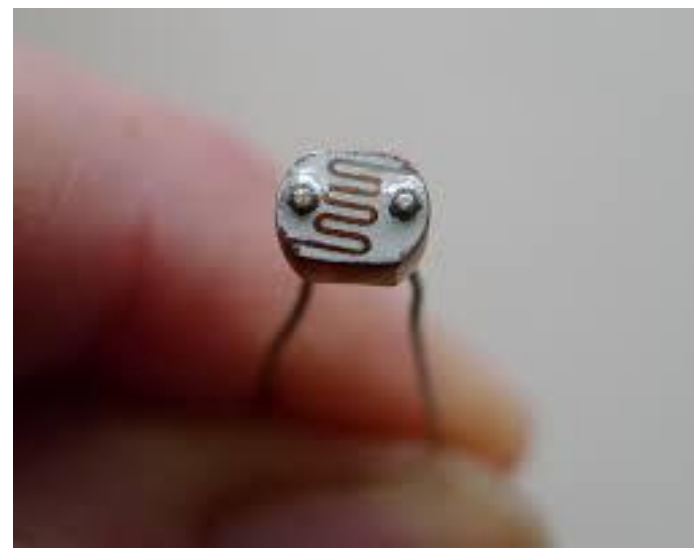

Figure 3. An LDR.

C. Forming and testing hypotheses about the underlying mechanisms of the problem

A simple quality-of-lamp meter could be built using a null-type Wheatstone bridge shown in Figure 1 with an LDR as a light intensity sensor $\left(R_{u}\right)$ and a VU meter as an output voltage display $\left(\mathrm{V}_{\mathrm{o}}\right)$. A hypothesis related in making a null point of the quality-of-lamp meter is that an energy-saving lamp produced by a well-known company could be used to realize the null point. Another hypothesis is that the quality 
of another energy-saving lamp of any company could be then determined. The quality of any energy-saving lamp is relative to that of the energy-saving lamp that made the null point.

The hypothesis on the realization of a null point of the quality-of-lamp meter was tested by fixing the LDR and resistors $R_{2}$ and $R_{3}$, varying the potentiometer $R_{v}$ so that the output voltage $\mathrm{V}_{\mathrm{o}}$ becomes zero while turning on the energysaving lamp of the well-known company. The obtained quality-of-lamp meter is called as a standardized quality-oflamp meter. The hypothesis on the determination of the quality of any energy-saving lamp of any company was tested by using the standardized quality-of-lamp meter and observing the deviation of the meter's pointer.

D. Identifying further learning needs for making progress with the problem

Based on the discussion with the tutor, some clues were found and further learning was planned to obtain the characteristics of LDR and VU meter and to understand the operation of the quality-of-lamp meter. Before practicing, discussion with the tutor was completed to make clearer what to do.

The LDR bought at a local electronic component market did not have a data sheet. After googling the internet, it was found that the data sheet was not available. It was designed to measure the resistance of the LDR using an ohmmeter. Some energy-saving lamps with different wattages including a dark condition were planned to be used to get a relation between resistance of LDR and the intensity of lamp.

The data sheet of VU meter bought at a local electronic component market was also not available. The internal resistance of the VU meter was proposed to be determined by using an ohmmeter. The relation between the deviation of the meter's pointer and the electric current flowing through the meter was also planned to be verified by using a variable power supply. The minimum and maximum currents of the VU meter would also then obtained.

E. Carrying out self-study between group meetings to fulfill the identified the learning needs

As the tutor gave some clues, learning by searching in the internet and learning by characterizing the LDR and VU meter were performed simultaneously.

The resistance of the LDR was measured using an ohmmeter. Two energy-saving lamps with different wattages were chosen. They were Philips Tornado 20 watts with 1200 lumens and Philips Tornado 5 watts with 235 lumens. By keeping the same distance of the lamp and the LDR, it was found that the resistance of the LDR decreases with increasing the wattage or the intensity of the lamp. This finding is the same as that given in the internet and the textbook.

The internal resistance of the VU meter was determined by using an ohmmeter. It was found that the internal resistance is 600 ohms. In addition, the VU meter only worked in the voltage range of $0-0.5 \mathrm{~V}$; otherwise, the VU meter's pointer broke. This suggested that the minimum and maximum currents flowing through the VU meter are 0 and $0.83 \mathrm{~mA}$, respectively.
F. Returning to the group to integrate the newly gained knowledge and applying it to the problem

All the group members obtained almost the same findings on the LDR and the VU meter. It was not surprising as the same type of LDRs and VU meters were employed. On the other hand, it confirmed that all the group members did correctly.

All the group members agreed to apply the LDR and the VU meter to the null-type Wheatstone bridge depicted in Figure 1 . The resistors $R_{2}$ and $R_{3}$ were the same value of $1000 \mathrm{ohm}$ and the potentiometer $\mathrm{R}_{\mathrm{v}}$ was $156 \mathrm{ohm}$. To obtain a standardized quality-of-lamp meter, a Philips Tornado of 20 watts was employed. By varying the potentiometer $R_{v}$, a null point, in which the output voltage $V_{o}$ is zero, was achieved as demonstrated in Figure 4.

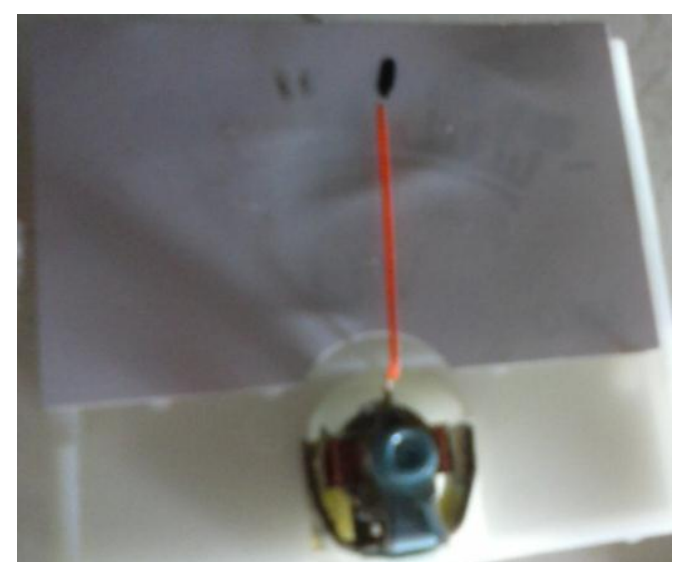

Figure 4. A standardized quality-of-lamp meter.

The standardized quality-of-lamp meter was then applied to measure the qualities of the following energysaving lamps: $\mathrm{K}^{* *} 20$ watts and $\mathrm{C}^{* *} 20$ watts.

\section{G. Repeating steps $\mathrm{C}$ to $\mathrm{F}$ as necessary}

The steps $\mathrm{C}$ to $\mathrm{F}$ were repeated twice. The first repeating was performed because there was a problem with the light. The light was not convergent so that the lamp was positioned at a near distance. The second repeating was caused by the nonlinearity of the voltage meter scale with the distance of the lamp and the LDR.

Reading carefully the purpose of the quality-of-lamp meter, a null point of the quality-of-lamp meter might be obtained first without considering the nonlinearity of the voltage mater scale. As the meter shows the quality of a lamp, the qualitative deviation of the meter's pointer is more important in which the more the right deviation does, the better the quality of lamp under test compared to the lamp that made the null point. On the contrary, the meter's pointer could also deviate left. The more the left deviation does, the worse the quality of lamp under test.

\section{H. Reflecting on the process and on the content that has been learnt.}

In general, reading carefully on the purpose of doing something or a topic was an important process. If difficulties were met in the process of making an instrument, then reading over and over again the steps might be done to gain 
more understanding on the process to realize the instrument. More reading had sometimes to be done in one or some steps. In addition, more learning by exercise helped more understanding on concepts and underlying mechanisms of the instrument.

The standardized quality-of-lamp meter was achieved by employing the Philips Tornado 20 watts. The lamp was positioned at $0.1 \mathrm{~cm}$ away from the LDR. By varying the potentiometer $R_{v}$, the null position was obtained. In analogy to a watch-face, the deviation of the meter's pointer lies in the upper half circle in the range of 0 to $180^{\circ}$. The ideal null position is therefore at $90^{\circ}$. However, it was difficult to vary the potentiometer $R_{v}$ so that the meter's pointer was at $90^{\circ}$. The best achievement of the null position was at $93^{\circ}$.

Replacing the Philips Tornado 20 watts with other same wattage energy-saving lamps, several different deviations of the meter's pointer were found as summarized in Table 1. It is shown that the deviation for the $\mathrm{K}^{* *} 20$ watts is smaller than that for the Philips Tornado 20 watts. It implies that the quality of the $\mathrm{K}^{* *} 20$ watts is lower than that of the Philips Tornado 20 watts. In addition, the deviation for the $\mathrm{C}^{* *} 20$ watts is smaller than that for the $\mathrm{K}^{* *} 20$ watts. The quality of the $\mathrm{C}^{* *} 20$ watts is slightly lower than that of the $\mathrm{K}^{* *} 20$ watts.

Table 1. Deviations of the meter's pointer for several energy-saving lamps.

\begin{tabular}{|c|c|}
\hline Brand & $\begin{array}{c}\text { Deviation of the meter's } \\
\text { pointer (degree) }\end{array}$ \\
\hline Phillips Tornado 20 watts & $93^{\circ}$ \\
\hline $\mathrm{K}^{* *} 20$ watts & $80^{\circ}$ \\
\hline $\mathrm{C}^{* *} 20$ watts & $77^{\circ}$ \\
\hline
\end{tabular}

The deviation of the meter's pointer for the Philips Tornado 5 watts was found at $85^{\circ}$. It is smaller than the deviation for the Philips Tornado 20 watts because of smaller wattage. Looking at the deviations for the $\mathrm{K}^{* *} 20$ watts and $\mathrm{C}^{* *} 20$ watts, the quality of the Philips Tornado 5 watts is still better.

Although the instrument is simple, good qualitative results were obtained. More energy-saving lamps with various wattages must be measured by the simple quality-oflamp meter and statistical tests must be performed in order to conclude the quality of an energy-saving lamp.

\section{Conclusion}

Following all steps of the problem-based learning, a simple quality-of-lamp meter has been realized. The meter has been used to measure the qualities of several energysaving lamps. It has been obtained that the qualities of $\mathrm{K}^{* *}$ 20 watts and $\mathrm{C}^{* *} 20$ watts are lower than that of Philips Tornado 20 watts.

\section{References}

[1] M. A. Albanese and S. Mitchell, "Problem-based learning: A review of literature on its outcomes and implementation issues," Acad. Med., vol. 68, no. 1 , pp. $52-81,1993$
[2] J. C. Perrenet, P. A. J. Bouhuijs, and J. G. M. M. Smits, "The suitability of problem-based learning for engineering education: theory and practice," Teach. High. Educ., vol. 5, no. 3, pp. 345-358, 2000.

[3] D. R. Brodeur, P. W. Young, K. B. Blair, "Problem-based learning in aerospace engineering education," Proc. The 2002 ASEE Annual Conf. \& Exposition, Session 2202, 2002.

[4] D. E. Allen, B. J. Duch, and S. E. Groh, "The power of problem-based learning in teaching introductory science courses," New Dir. Teach. Learn., vol. 1996, no. 68, pp. 43-52, Winter 1996.

[5] A. K. Taşoğlu and M. Bakaç, "The effects of problem based learning and traditional teaching methods on students' academic achievements, conceptual developments and scientific process skills according to their graduated high school types," Procedia Soc. Behav. Sci., vol. 2, pp. 24092413, 2010.

[6] P. van Kampen, C. Banahan, M. Kelly, E. McLoughlin, E. O'Leary, "Teaching a single physics module through problem based learning in a lecture-based curriculum," Am. J. Phys., vol. 72, no. 6, pp. 829-834, 2004.

[7] E. Tatar and M. Oktay, "The effectiveness of problem-based learning on teaching the first law of thermodynamics," Res. Sci. Technol. Educ., vol. 29, no. 3, pp. 315-332, 2011.

[8] P. Schwartz, S. Mennin, and G. Webb (eds.), Problem-based Learning: Case Studies, Experience and Practice, London: Kogan Page, 2001.

[9] G. Cardinale, Optoelectronics: Introductory Theory and Experiments, 1st ed., Clifton Park: Delmar Cengage Learning, 2003.

[10] A. S. Morris, Measurement and Instrumentation Principles, Butterworth-Heinemann, 2001. 